\title{
CRITÉRIOS DE SELEÇÃO DE PAIS ADOTIVOS: EM DISCUSSÃO**
}

\author{
Lidia Natalia Dobrianskyj Weber
}

\begin{abstract}
RESUMO
Este texto pretende fazer uma reflexão crítica sobre as práticas de seleção das pessoas cadastradas nos Serviços de Adoção dos Juizados da Infância e da Juventude, uma vez que, muitas vezes, este processo seletivo tem sido feito com base em pressupostos dogmáticos acerca do comportamento humano. A presente análise norteia-se pelo pensamento aberto da pós-modernidade, que avalia o pensamento sentencioso como anticientífico e antiintelectual; com a pós-modernidade é preciso crivar nossos preconceitos e não ter medo da ausência de certezas.
\end{abstract}

"Deus nos dê sabedoria para descobrir o certo, vontade para escolhê-lo e força para fazê-lo durar" (Rei Arthur, no filme Lancelot)

Recentes estudos (WEBER, 1995A e B; WEBER, 1996; WEBER, 1997; WEBER, CORNÉLIO, GAGNO e SILVA, 1994; WEBER e CORNÉLIO, 1995A e B) têm demonstrado através de entrevistas, questionários e depoimentos que existe uma postura dogmática em relação à seleção de pais adotivos por alguns Serviços de Adoção dos Juizados da Infância e da Juventude do país. Serão usados alguns relatos obtidos nos trabaIhos acima citados para ilustrar o pensamento da autora.

** Professora do Departamento de Psicologia da UFPR; Especialista em "Origens da Psicologia" (UFPR) e em "Antropologia Filosófica" (UFPR); Mestre e Doutoranda em Psicologia Experimental (USP).

Interação, Curitiba, v. 1, p. 123-137, jan./dez. 1997 


\section{QUEM É APTO PARA SER MÃE E PAI?}

"Ter um filho é uma responsabilidade muito grande e um passo muito sério", diz a sabedoria popular. "As relações estabelecidas entre os filhos e seus pais são fortes determinantes para a personalidade dos filhos", dizem os psicólogos. A dinâmica familiar refletida nas interações entre pais e filhos tem sido tema de grande interesse tanto para o conhecimento popular quanto para 0 conhecimento científico, e tanto as pessoas que se guiam pelo senso comum quanto os cientistas imaginam uma família idealizada para dar conta dessa "séria responsabilidade" que é criar um filho. Por um lado, não é tão simples deixar tudo por conta do "instinto materno", para o qual tudo é natural e nem é preciso freqüentar cursos universitários para ser um bom pai e uma boa mãe, mas uma reflexão sobre o significado destes papéis se faz necessária quando se deseja um filho.

Raras são as pessoas ou as famílias que se preparam psicologicamente para conceber um filho biológico ("preparação" deve ser algo mais do que os famosos cursos para gestantes por um período de 2 dias). Uma preparação para ter um filho, seja ele biológico ou adotivo, refere-se a uma reflexão sobre as próprias motivações, riscos, expectativas, desejos, medos, entre outros. Preparar-se para ter um filho significa, de maneira muito resumida, tomar consciência dos limites e possibilidades de si mesmo, dos outros e do mundo. Preparar-se não quer dizer somente o momento que antecede o "ter um filho"; é a consciência de que esta preparação deve ser contínua, que as coisas e as pessoas estão interagindo dinamicamente e, portanto, sempre estão sujeitas a mudanças; é a compreensão de que todos nós estamos sempre em um processo dinâmico de construção e reconstrução, desde os sentimentos e desejos até os códigos sociais de ética e de moral.

Raras também são as preparações para as adoções. No entanto, fala-se muito e abertamente da necessidade da preparação para a adoção e fala-se muito pouco ou quase nada da prepa- 
ração para se ter um filho biológico. Diz-se que a família biológica é a única responsável pelo seu filho, enquanto a responsabilidade pela escolha dos "pais ideais" e pelo "acerto" do processo da adoção passa a ser dos técnicos que trabalham nos Juizados da Infância e da Juventude. O que não se pode esquecer é que este tipo de trabalho não é somente técnico. Nem neutro. Ele envolve inúmeros aspectos subjetivos, parciais, teóricos, arbitrários, políti$\cos$, pessoais, em relação à escolha da "família adequada" para adotar uma criança. Um dos problemas é que nem sempre os técnicos que trabalham para selecionar as famílias mais adequadas para adotar um criança lembram da possibilidade de mudança e de aprendizagem do ser humano, além de não fornecerem aos adotantes uma proposta de preparação e/ou mudança de atitudes. Seleciona-se, simplesmente. Até hoje percebe-se no discurso e na prática dos Serviços de Adoção este tipo de postura apriorística, herança de uma história da adoção na humanidade, das leis sobre adoção (em especial o Código de menores em nosso país) e de uma compreensão moralista e alienada em relação à concepção sócio-histórica da família.

Muitos técnicos que trabalham nos Serviços de Adoção dos Juizados da Infância e da Juventude, em especial Assistentes Sociais e Psicólogos, adotam esta postura dogmática e estereotipada que sequer conseguem perceber seus próprios preconceitos. Trabalhar com adoção e chamar a família biológica de "normal" ou "natural" não parece preconceituoso? Ao se pensar nas antinomias, não se quer dizer que a família adotiva é "artificial' ou "anormal"? Técnicos dizem que é preciso 'Verificar se existem ou não contra-indicações (...) à luz de critérios previamente estabelecidos", e alguns textos de profissionais que trabalham com adoções costumam arrolar argumentos subjetivos e amplos, sem trazer especificidade para as "contra-indicações"". Outros, trazem

MORAIS, D. A. M. Os desafios da adoção no Brasil. A Adoção em Terre des Hommes, 60, 1994. 
claramente alguns exemplos contra a escolha de adotantes: por exemplo, um casal que adotaria uma criança de dois anos queria mudar seu nome e por este fato foi considerada inapta para a adoção ${ }^{2}$. Foi correto? Em primeiro lugar, temos que ressaltar que o próprio Estatuto da Criança e do Adolescente permite esta mudança. Em segundo lugar, se esse casal não compreende a importância da construção da identidade de uma criança não seria possível esclarecê-lo? Um simples fator é suficiente para rotular esse casal de insensível e inapto para a paternidade? É preciso lembrar que estamos no Brasil, um país onde o acesso à informação, à educação, ao esclarecimento da maior parte da população é muito seletivo. A maioria das pessoas não toma leite com manga "porque faz mal", bate na madeira três vezes para "não dar azar", toma decisões com base no horóscopo do dia, acredita que os crimes de crianças e adolescentes aumentaram "por causa do Estatuto da Criança e do Adolescente", não adotaria crianças que fossem filhos de prostitutas e assassinos porque "a marginalidade passa pelo sangue", acha que pelo fato de algumas mulheres engravidarem após a adoção, "adotar uma criança é um bom motivo para se tentar ter filhos naturais", acredita que "quando uma criança não sabe que é adotada surgem menos problemas", pensa que "somente os pais são culpados pelas crianças que estão nas ruas porque não souberam educá-los", ou que "é possível adotar crianças com mais de 10 anos de idade para que possam

FERREYRA, M. C. O Serviço Social e a Adoção. A Adoção em Terre des Hommes, 63, 1994.

BRANDÃO, M. S. Associação de Pais Adotivos. A Adoção em Terre des Hommes, 85, 1996.

DELL'ANTONIO, A Seleção. Preparação e Apoio às Famílias Adotivas. A Adoção emTerre des Hommes, 30, 1991.

2 VARELA, A M.G. Adoção. A Adoção em Terre des Hommes, 88, 1996.

3 Esta e as próximas quatro afirmações foram detectadas na pesquisa de WEBER, L. N. D.; CORNÉLIO, S. A.; GAGNO, A. P. e SILVA, M. L. Adoção: conceitos e pré-conceitos. In: REUNIÃO ANUAL DA SBPC (46. :1994: Vitória). Caderno de resumos. p. 854 e REUNIÃO ANUAL DE PSICOLOGIA (24. : 1994: Ribeirão Preto). Caderno de resumos. p. 200. 
ajudar nos serviços domésticos". Não seria esperar demais que pessoas com estas idéias consigam entender as possíveis nuanças sobre a construção da identidade de uma pessoa e a relação com o seu nome? Acreditamos que seria possível esclarecer e acreditar na mudança, antes de excluir, senão as conhecidas avaliações pseudo-psicológicas podem tornar-se um modo perverso de discriminação e segregação.

$\mathrm{Na}$ verdade, deveria haver uma preparação psicológica também para famílias biológicas. Porém, no caso da seleção de pais para adoção, dever-se-ia ter cuidado em afirmar, selecionar e contra-indicar com base exclusivamente em um conhecimento apriorístico e dogmático, pois existem relações funcionais que não podemos controlar e estamos constantemente em um curso dinâmico de constituição. Além disso, existem situações concretas de adoções com notável sucesso em relação à criação do apego que contradizem os critérios de seleção, como, por exemplo, adoções inter-raciais e tardias e adoções cujas motivações iniciais teriam sido consideradas "inadequadas" por muitos técnicos. Estes fatores são exemplos que o saber está sempre construindo-se e reconstruindo-se a partir de novas instâncias sociais e históricas. Nos processos de adoção os técnicos são fundamentais, não tanto para selecionar (que é o que fazem a maior parte das agências de adoção), mas para preparar: esclarecer, informar, instruir, educar, conscientizar, desmistificar preconceitos e estereótipos; modificar motivações, desvelar vocações, lapidar desejos... A maior parte das pessoas cadastradas nas agências de adoção está ansiosa para freqüentar este espaço de reflexão ${ }^{4}$, mas elas são somente cadastradas, julgadas, examinadas, esquadrinhadas, investigadas, interpretadas nos deslizes de seus relatos verbais... "Será que eles estão prontos e têm as características corretas para serem bons pais?'. Talvez poucas pessoas estejam ou esti-

4 WEBER, L. N. D. Características e desejos de pessoas cadastradas para uma adoção. In: REUNIÃO ANUAL DE PSICOLOGIA (27.: 1997: Ribeirão Preto).

Interação, Curitiba, v. 1, p. 123-137, jan./dez. 1997 
vessem aptas para serem pais, mas deve-se acreditar que pouquíssimas não seriam capazes de tornarem-se capazes de exercer este papel. De acordo com o conceito de proteção integral do Estatuto da Criança e do Adolescente, além de escolher famílias ideais para bebês recém-nascidos perfeitos, é iminente fazer uma preparação dos adotantes em relação às adoções de crianças com necessidades especiais, uma vez que o objetivo maior é garantir às crianças institucionalizadas e abandonadas o direito da convivência familiar e comunitária.

Outro aspecto sobre o qual é necessário repensar é que "família ideal" é essa que se imagina na adoção? Ouvem-se juízes dizendo que "jamais daria um bebê encontrado na porta de casa para a família que o encontrou porque ele sempre carregaria 0 estigma do bebê encontrado na porta"; outros técnicos dizem que "quando o adotando quer um bebê muito perfeito não dá certo"; outros ainda, ressaltam que "quando a criança tem um problema de saúde muito grave a adoção é desaconselhada", e grande parte dos profissionais dos Serviços de Adoção afirma que o "fato de a criança ter as mesmas características dos adotantes é um fator essencial" e "que viúvas e solteiras devem adotar crianças mais velhas, pois o juiz sempre vai preferir um casal", existindo psicólogos que desaconselham abertamente a adoção interracial $^{6}$. O ser humano sempre se deparou com a questão do "diferente", daquele que não reflete a sua própria imagem e torna-se, portanto, ameaçador. Isto dificulta uma reflexão, pois permite que continuemos seguindo as perspectivas sociais que originam e reforçam preconceitos. Também MALDONADO (1995, p. 21) concorda com a idéia da rigidez da seleção dos adotantes:

Em vez de colocar a ênfase em examinar e julgar os "candidatos a pais adotivos", para ver se estão aptos a receber a

5 GAZETA DO POVO. "Fila de casais à espera de adoção em Curitiba", p. 12, 12 de janeiro de 1997.

6 SOUZA, H. R. Adoção. Curitiba : Paulinas, 1986. 
criança (com a inevitável conotação de prêmio ou castigo), o que poderiam fazer as equipes de profissionais? Buscar uma família para a criança que precisa ser acolhida e uma criança para a família que deseja recebê-la: isso significa conhecer melhor as pessoas em questão, esclarecer sobre as dificuldades mais comumente encontradas, organizar reuniões de grupos de pessoas que desejam adotar, para que se converse sobre os sentimentos, apreensões e expectativas comuns a todos que estão em processo de gestar uma maternidade e uma paternidade na adoção.

Pesquisas com famílias adotivas (WEBER, 1995A, 1995B e 1995C; WEBER, 1996; WEBER e colaboradores, 1994); WEBER e CORNÉLIO, 1995A e 1995B) revelaram dados surpreendentes em relação à questão das "motivações inadequadas ou adequadas para o exercício da paternidade adotiva". A análise dos resultados mostrou que não existe correlação entre a motivação dos adotantes e o sucesso da adoção. Isso significa, grosso modo, que a construção do vínculo afetivo pode ser tão poderosa e importante na dinâmica familiar que deixa em segundo plano a "inadequação" do motivo inicial ou outros motivos, pois outra história é capaz de ser construída posteriormente; exatamente ao contrário do que supõem muitos técnicos, ao afirmarem que a apreciação das motivações tem um interesse capital", pois "é mais simples uma ligação com os filhos naturais do que com os filhos adotados". . Para estes técnicos são consideradas não recomendáveis as motivações que resultam no risco da "criança distração", "criança tábua-de-salvação", "criança colocação" e ainda "a atração neurótica por crianças deficientes"9; outros técnicos afirmam que famílias monoparentais e pessoas que podem ter filhos bioló-

7 NATALIO, H. Um sentido para a vida. A Adoção em Terre des Hommes, 90, 1990.

8 DELL'ANTONIO, A Seleção. Preparação e Apoio às Famílias Adotivas. A Adoção em Terre des Hommes, 30, 1991.

9 AJURIAGUERRA, J. Manual de Psiquiatria Infantil. São Paulo: Masson, 1983.

Interação, Curitiba, v. 1, p. 123-137, jan./dez. 1997 
gicos e optam por filhos adotivos também estariam em "situação de risco" ${ }^{\prime \prime}$. Um casal que deseja adotar uma criança porque seu filho biológico faleceu pode parecer realmente inadequado. Os técnicos diriam que eles "estão querendo substituir o filho falecido". No entanto, é preciso levar em conta a capacidade de reconstrução de sua própria história, de construção do apego, do fascínio da capacidade de amar. Pode-se aprender que, na verdade, ninguém substitui ninguém e todo filho pode ter seu lugar no afeto dos pais. Se ninguém pode acessar a subjetividade do outro, e, muitas vezes, nem mesmo a própria pessoa, então os rótulos de nada valem, porque cada caso é um caso, ou seja, as pessoas não se comportam da mesma maneira nem mesmo em situações idênticas - as relações funcionais em cada situação é que são importantes: "o vento é o mesmo, mas sua resposta é diferente em cada folha", ressalta sabiamente a poetisa Cecília Meireles. Este argumento nos faz entender que a prevenção é fundamental, mas também é preciso acreditar num trabalho a posteriori frente a estas "inadequações" - o acompanhamento.

É correto supor que toda adoção implica um abandono anterior, mesmo que tenha sido um "abandono por amor". Porém, as histórias de famílias adotivas têm mostrado que, muitas vezes, este fato não tem para os filhos adotivos a mesma importância afirmada pelos técnicos. Assim, falar que é sempre necessário "elaborar o luto do abandono e da rejeição"11 pode dificultar a compreensão de que, às vezes, o luto pode não existir porque não houve vinculação: uma criança que foi abandonada bebê nunca se ligou afetivamente à sua mãe biológica. $\mathrm{O}$ caso de uma menina

10 JOFRÉ, M. D. Reflexiones sobre la seleccion de padres adoptivos. Anuário de Psicologia, 71, p. 121-128, 1996.

11 NATAliO, H. Um sentido para a vida. A Adoção em Terre des Hommes, 90, 1997.

DELL'ANTONIO, A Seleção. Preparação e Apoio às Famílias Adotivas. A Adoção em Terre des Hommes, 30, 1991.

ZIMEO, A. M. Nas entrelinhas da adoção. In: Fernando Freire (Org.). Abandono e Adoção. Curitiba: Terre des Hommes, 1994. 
que foi encontrada num terreno baldio por urna família que já tinha 4 filhos biológicos ilustra a questão: "não tenho a menor curiosidade sobre eles (a família biológica); não tenho outro pai nem outra mãe; meus pais verdadeiros são estes que me criaram e me ensinaram a amar e ser amada"12. Assim, dizer que "uma ligação com os filhos naturais é mais simples do que os filhos adotados porque com estes últimos a precedente ligação com um outro núcleo torna mais dlfícil a aceitação de sua autonomia"13 ... pode ser teoricamente correto, mas... nem sempre. Talvez seja mais parcimonioso acreditar que a "adoção afetiva é a verdadeira relação parental" (SCHETTINI, 1994), pois qualquer filho, assim como qualquer pai e mãe, precisa ser afetivamente adotado. É importante questionar a razão da existência de uma postura de tolerância tão grande para com os pais biológicos e tão pequena para com os pais adotivos (ou futuros pais adotivos). Pais adotivos devem ser "melhores" do que pais biológicos? Não estamos negando a importância de uma avaliação, da orientação técnica e mesmo de uma seleção, mas concordamos com o que relata HOFFMAN (1990, p. 10) sobre a unicidade e a singularidade de cada família: "o terapeuta pós-moderno atua junto à família sem qualquer definição de patologia, sem qualquer idéia de quais estruturas disfuncionais irá procurar e sem qualquer idéia estabelecida sobre o que deve ou não mudar". Antes de pensar da seleção das pessoas, deverse-ia pensar na proteção à criança em situação de abandono, uma vez que, de acordo com qualquer teoria sobre o desenvolvimento infantil, ela deve crescer em uma família e não em uma instituição.

12 Entrevista concedida à autora.

13 DELL'ANTONIO, A Seleção. Preparação e Apoio às Famílias Adotivas. A Adoção em Terre des Hommes, 30, 1991. 


\section{QUEM É APTO PARA SELECIONAR BONS PAIS?}

O século XX é o século da ciência. Imaginava-se que se encontrariam todas as respostas por meio da ciência, objetiva e fidedignamente. Ao se realizar trabalhos psicológicos e/ou sociais, esquece-se que técnicos estão todos imersos na questão da "nãoneutralidade": o grande e insuperável problema nestas áreas de conhecimento é que não existe o desenvolvimento de princípios de relatividade que independam do observador, pois o ser humano é o observador e o sujeito dessa ciência. A física quântica acaba derrubando um pouco este determinismo até mesmo nas ciências exatas: é possível conhecer a determinação até certo ponto e isso significa que existe um limite do quanto o observador pode conhecer a realidade!

Ao tentar selecionar "bons pais", o técnico sempre está lidando não somente com o conhecimento público (comportamentos abertos: relatos verbais, expressões faciais e corporais; condições materiais, atestado de idoneidade moral, atestado de bons antecedentes, contracheque etc.), mas também, e principalmente, está tentando compreender (e avaliar) os chamados comportamentos encobertos, privados - os sentimentos, as emoções, a subjetividade do ser humano. Será que a pessoa fala o que está sentindo ou aquilo que o técnico quer ouvir? Impossível saber em uma ou duas entrevistas. Sobre essa tentativa de conhecimento da subjetividade, existe um ponto quase comum na maioria dos pensadores (como por exemplo, S. FREUD; B. F. SKINNER; M. MERLEAU-PONTY): eles afirmam que não somos capazes de absorver a realidade humana somente através do objetivo (DOBRIANSKYJ, 1988, p. 42). Não somos nem mesmo capazes de explicar e interpretar a realidade humana somente com o conhecimento objetivo. Na verdade, parece que sempre restará um núcleo subjetivo que é irredutível ao objetivo, um núcleo de uma dimensão indevassável. Quem é que explica como percebemos a tristeza nos olhos do outro? A nossa ciência, as nossas teorias e 
as nossas técnicas, às vezes, não explicam o subjetivo, o incompreensível, o estranho, o diferente. É preciso ter, pelo menos, certa noção desta complexidade, como indica HOBSBAWN (1995, p. 520):

(...) Pois embora todos nós, e não menos os cientistas inteligentes, saibamos que existem diferentes modos de perceber a mesma realidade, às vezes não comparáveis ou mesmo contraditórios, mas que todos precisamos apreendêla em sua totalidade, ainda não temos idéia de como os relacionamos. O efeito de uma sonata de Beethoven pode ser analisado física, fisiológica e psicologicamente, e também pode ser absorvido ouvindo-se-a; mas como se relacionam esses modos de compreensão? Ninguém sabe.

Pensando em todo este complexo envolvimento do cientista e do sujeito da investigação (objeto), as teorias atuais não deveriam ser taxativas, mas probabilísticas. Em se tratando do caso da escolha de "bons pais", não é possível falar que "essa constituição familiar vai dar certo", mas deve-se falar: "dada esta constituição familiar, existe uma alta probabilidade de haver sucesso..."; ou "se houver uma preparação e conscientização desta família, há uma grande probabilidade de sucesso". Qual a diferença? Toda a diferença do mundo. A diferença é não ter uma atitude de "dono-domundo" e pretender tirar verdades da bola de cristal. É comum, entre psicólogos, psiquiatras e assistentes sociais, ouvir-se que "o abandono é sempre traumático e irrecuperável ${ }^{14} \mathrm{e}$, mesmo que a criança seja adotada com horas de vida, "o bebê adotivo é um bebê de risco"15. Ou que sempre, num caso de adoção, "existe uma situação de risco psicológico e social'. Qual teoria explica

14 Estas afirmativas foram ouvidas em apresentações realizadas durante o $X$ CONGRSSO LATINO AMERICANO DE PSIQUIATRIA DA INFÂNCIA E DA ADOLESCÊNCIA (1995, Curitiba).

15 DINIZ,J.S A adoção: notas para umavisão global. In:FREIRE, F.(Org.) Abandono e Adoção II. Curitiba: Terre des Hommes, 1994. 
uma família que, possuindo quatro filhos biológicos, tenha adotado um menino com dez anos de idade, negro e hemofílico? Altruísmo? Caridade? Coragem? As teorias da probabilidade caem por terra com qualquer uma das hipóteses, principalmente quando se sabe que esta é uma família muito feliz, que "deu certo". Deste modo, o essencial é a compreensão da adoção em primeiro lugar e não o apego desmedido a técnicas que viesam nosso olhar e que, às vezes, podem fazer com que seja necessário mudar a realidade para atingir as dimensões de determinado paradigma...

Cada profissional tem a sua teoria (e seus dogmas), assim como Procusto ${ }^{16}$ tinha sua cama: porém, não adianta querer encaixar todos os fatos e todos os fenômenos dentro dela. Não devemos idolatrar as teorias, pois existem inúmeras condições sociais atuando sobre os enunciados científicos. É preciso ter um bom conhecimento de pelo menos um paradigma, mas não se deve ter medo de se "destravar" um pouco, deixar-se guiar pelo desconhecido, sair do esquadro, ultrapassar as fronteiras, espiar para fora da concha... É preciso ter por base também o que não se sabe, o problema, a possibilidade, a mudança. A diferença entre conhecimento e pensamento é fundamental: o conhecimento se conduz pelo dado e baseia-se no que eu sei. O pensamento se conduz pelo problema; ele é aberto e baseia-se no que eu não sei. É preciso construir um método que concilie o conhecimento com o pensamento. Deve-se ter uma âncora, mas aventurar-se é fundamental. Pensar ou conhecer: eis a questão contemporânea.

Como nos indica HOBSBAWM (1995, p. 510), "não pode haver dúvida de que o século $X X$ foi aquele em que a ciência transformou tanto o mundo quanto nosso conhecimento dele". Hoje o homem não é mais "moderno". Nem contemporâneo. É

16 Segundo a mitologia grega, Procusto era um salteador da Ática, pequena península da Grécia onde se acha Atenas. Este famigerado bandido despojava os viajantes e torturava-os deitando-os num leito de ferro: se a vítima era maior, cortava-lhe os pés; se menor, esticava-a por meio de cordas até que atingisse as dimensões do leito. Foi morto por Teseu, que Ihe aplicou o mesmo suplício. 
pós-moderno. Com a globalização e universalização, houve uma transformação da forma de representação do tempo no interior do desenvolvimento científico, associada a um processo sociopolítico de transformação da técnica versus conhecimento versus processo econômico-político de produção. Este sistema pós-moderno é emergente, é oposto ao pensamento tradicional e tem a característica de abarcar sistemas que são móveis, pois não se tem claro onde está sua delimitação. Esse seu espaço atemporal e ilimitado permite uma abertura a novas solicitações, tanto políticas quanto culturais ou científicas, sempre levando em conta o grau de historicização do pensamento.

O pensamento pós-moderno sugere a necessidade de se ter pelo menos um pouco de fluidez paradigmática que nos proporcione uma certa crítica e que nos prepare para enfrentar a atual crise de paradigmas. Não é mais possível ser parcial, maniqueísta, preconceituoso, dogmático. São novos tempos, novos pensamentos. Nós estamos no meio do trânsito de uma modificação histórica e isso é um pouco assustador e inquietante. O pensamento tradicional é fechado, mas é muito mais consistente e continua válido; parafraseando HOBSBAWM (1995, p. 518), o que nos deixa nervosos é que não sabemos muito bem como juntar o velho e o novo. Se existem dois mundos é preciso integrá-los e não optar por um deles. É preciso um pensamento aberto e híbrido, para que seja possível reagir a tantas outras solicitações existenciais.

O pensamento pós-moderno não tem lugar para os dogmas, pois reflete a consciência do movimento e o ritmo da existência, da necessidade da diversidade, da possibilidade de convergir para qualquer ponto. Em vez de selecionar pais adotivos a partir de duas ou três entrevistas, deve-se levar em conta o pensamento fruto da pós-modernidade (que não exclui o tradicional), que é transdisciplinar, transparente, que lida com a possibilidade do sere-não-ser e com as infinitas cores do jogo de luzes de um calei- 
doscópio. Uma analogia da frase do Rei Arthur em epígrafe poderia significar inicialmente uma preparação ("sabedoria para descobrir o certo") e depois, uma escolha ("vontade para escolhêlo"), seguida de um apoio contínuo e sistemático ("força para fazê-lo durar").

\section{REFERÊNCIAS BIBLIOGRÁFICAS}

1 DOBRIANSKYJ, L. N. Subjetividade : ser e não ser. Psicologia Argumento, n. 8, p. 38-44, 1988.

2 HOBSBAWM, E. Era dos extremos : o breve século XX 1914-1991. São Paulo : Companhia das Letras, 1995.

3 MALDONADO, M.T. Os caminhos do coração. São Paulo: Saraiva, 1995.

4 SCHETTINI FILHO, L. Compreendendo o filho adotivo. Recife: Bagaço, 1994.

5 TASSARA, E.T.O. Metodologia da ciência : questões de método da Psicologia Social contemporânea. Disciplina ministrada para curso de Doutorado em Psicologia. Departamento de Psicologia Social do Instituto de Psicologia da Universidade de São Paulo, 1996.

6 WEBER, L. N. D. Mesa redonda "Família e Adoção". In: CONGRESSO LATINO AMERICANO DE PSIQUIATRIA DA INFÂNCIA E DA ADOLESCÊNCIA (10: 1995 : Curitiba). Caderno do programa, Curitiba, 1985A. p. 72.

7 . Famílias adotivas e mitos sobre laços de sangue. Jornal Contato-CRP-08, n. 79, 1995. Caderno técnico.

8 . Da institucionalização à adoção: um caminho possível? Rev. Igualdade, n. 9, p. 1-8, 1995. 
9 . Enfants adoptifs: des amours ou des ennuis? In: CONGRÈS INTERNATIONAL DE PSYCHOLOGIE (26. : 1996: Montreal. Caderno de Resumos, 1996. p. 354.

10 ; CORNÉLIO, S. A.; GAGNO, A. P.; SILVA, M. L. Adoção: conceitos e pré-conceitos. In: REUNIÃO ANUAL DA SBPC (46.: 1994: Vitória). Caderno de resumos, p. 854; REUNIÃO ANUAL DE PSICOLOGIA (24. : 1994: Ribeirão Preto). Caderno de resumos, p. 200. . Filhos adotivos: amores ou dissabores? Revista de Ciências Humanas, n. 4, p. 119-164, 1995.

12 Adoção: perspectiva dos filhos adotivos. In: CONGRESSO LATINO-AMERICANO DE PSIQUIATRIA DA INFÂNCIA E DA ADOLESCÊNCIA (10: 1995: Curitiba). Caderno de resumos, p. 4. e REUNIÃO ANUAL DE PSICOLOGIA (25 : 1995: Ribeirão Preto). Caderno de resumos, p. 154. 